\title{
Regional estimation of geomagnetically induced currents based on the local magnetic or electric field
}

\author{
Ari Viljanen ${ }^{1, *}$, Peter Wintoft ${ }^{2}$, and Magnus Wik ${ }^{2}$ \\ 1 Finnish Meteorological Institute, Erik Palménin aukio 1, 00560 Helsinki, Finland \\ *Corresponding author: ari.viljanen@fmi.fi \\ 2 Swedish Institute of Space Physics, Scheelevägen 17, 22370 Lund, Sweden
}

Received 8 April 2015 / Accepted 15 June 2015

\begin{abstract}
Previous studies have demonstrated a close relationship between the time derivative of the horizontal geomagnetic field vector $(\mathrm{d} \mathbf{H} / \mathrm{d} t)$ and geomagnetically induced currents (GIC) at a nearby location in a power grid. Similarly, a high correlation exists between GIC and the local horizontal geoelectric field (E), typically modelled from a measured magnetic field.

Considering GIC forecasting, it is not feasible to assume that detailed prediction of time series will be possible. Instead, other measures summarising the activity level over a given period are preferable. In this paper, we consider the 30-min maximum of $\mathrm{d} \mathbf{H} / \mathrm{d} t$ or $\mathbf{E}$ as a local activity indicator $\left(|\mathrm{d} \mathbf{H} / \mathrm{d} t|_{30}\right.$ or $\left.|\mathbf{E}|_{30}\right)$. Concerning GIC, we use the sum of currents through the neutral leads at substations and apply its 30 -min maximum as a regional activity measure $\left(\mathrm{GIC}_{30}\right)$.

We show that $|\mathrm{d} \mathbf{H} / \mathrm{d} t|_{30}$ at a single point yields a proxy for GIC activity in a larger region. A practical consequence is that if $|\mathrm{d} \mathbf{H} / \mathrm{d} t|_{30}$ can be predicted at some point then it is also possible to assess the expected GIC level in the surrounding area. As is also demonstrated, $|\mathbf{E}|_{30}$ and $\mathrm{GIC}_{30}$ depend linearly on $|\mathrm{d} \mathbf{H} / \mathrm{d} t|_{30}$, so there is no saturation with increasing geomagnetic activity contrary to often used activity indices.
\end{abstract}

Key words. Geomagnetically induced currents

\section{Introduction}

Modelling of geomagnetically induced currents in power grids or pipelines for past events is in principle a straightforward task. The input data consist of geomagnetic recordings, ground conductivity models and the DC model of the power grid or pipeline system (e.g. Viljanen et al. 2012). The same holds true for future events if a prediction of the magnetic field can be given as a time series. However, despite recent advanced steps in the modelling of the near-Earth space (e.g. Pulkkinen et al. 2010a, 2013), a sufficient accuracy is obviously hard to reach. For the time being, a more feasible approach is to try to quantify the expected level of GIC such as its likely peak value with error limits during a future time window.

Several previous studies have demonstrated a close relationship between the time derivative of the horizontal geomagnetic field vector $(\mathrm{d} \mathbf{H} / \mathrm{d} t)$ and GIC at a nearby location (Viljanen 1997, 1998; Viljanen et al. 2001; Hejda \& Bochnicek 2005; Thomson et al. 2005; Trichtchenko et al. 2007; Ngwira et al. 2008). Under certain conditions of the ground conductivity, GIC is more closely related to the magnetic variation field itself (Watari et al. 2009; Pulkkinen et al. 2010b). However, as follows from the basic modelling method (Lehtinen \& Pirjola 1985; Viljanen et al. 2012; Boteler 2014; Boteler \& Pirjola 2014), GIC is definitely linked to the horizontal geoelectric field (E). The electric field is in turn related to temporal variations of the magnetic field as stated by Faraday's law of induction.

Trichtchenko \& Boteler (2004) considered the correlation between GIC and 1-h or 3-h geomagnetic activity indices, and between GIC and the 1-h or 3-h peak values of the time derivative of the magnetic field at a nearby observatory (a component of the field, denoted by $\mathrm{d} B / \mathrm{d} t$ ). They found that $\mathrm{d} B / \mathrm{d} t$ gives the highest correlation. They also remarked that "it is much easier to predict the envelope of the GIC variations rather than the detailed GIC variations themselves". This difficulty is quite obviously related to the fact that "it is usually easier to predict a quantity (magnetic field variation) than its time derivative with a first principles-based model" (Tóth et al. 2014).

Gleisner \& Lundstedt (2001) considered 5-min averages when predicting the local magnetic field from solar wind data. Wintoft et al. (2005) presented a method to predict the 10-min root-mean-square (RMS) of the time derivatives of the horizontal magnetic field components. Wintoft (2005) also also considered the relation between the 10-min standard deviation of measured GIC and the RMS magnetic field.

A more general hypothesis investigated in this paper is that the level of GIC activity in a regional power grid could be quantified with respect to $\mathrm{d} \mathbf{H} / \mathrm{d} t$ or $\mathbf{E}$ determined at a single site. In this study, the starting point is the 30-min maximum of $|\mathrm{d} \mathbf{H} / \mathrm{d} t|$ at a single location as considered by Wintoft et al. (2015). Similarly to us, Weigel et al. (2003) studied 30-min sequences when relating solar wind quantities to $\mathrm{d} B / \mathrm{d} t$, but they used 30-min averages instead of the maximum value. Tóth et al. (2014) considered the maximum $|\mathrm{d} \mathbf{H} / \mathrm{d} t|$ in 20 -min intervals when quantifying the success of predictions. Instead of directly comparing the maximum of the measured and forecasted $|\mathrm{d} \mathbf{H} / \mathrm{d} t|$, they studied whether it will exceed a threshold value in a 20-min interval at a given magnetometer station. 
20031030, grid model: NORDIC, observatory: UPS
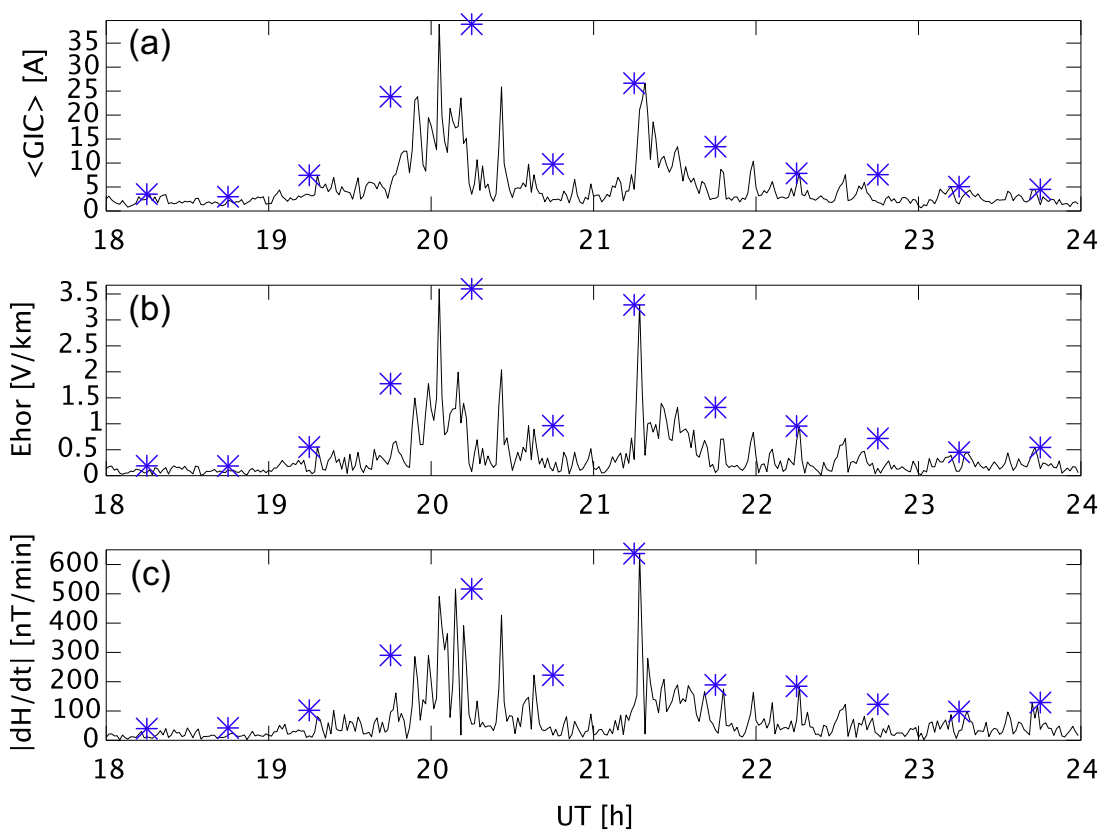

Fig. 1. (a) Sum of GIC divided by the number of nodes in the Nordic power grid at 18-24 UT on 30 October 2003 as 1 -min values, (b) horizontal electric field at UPS, (c) time derivative of the horizontal magnetic field $(|\mathrm{d} \mathbf{H} / \mathrm{d} t|)$ at UPS. 30-min maximum values are plotted as blue asterisks at the midpoints of each 30-min period of 18:00-18:29, 18:30-18:59, etc.

Wintoft et al. (2015) showed that $\mathrm{d} \mathbf{H} / \mathrm{d} t$ has a high correlation with $\mathbf{E}$ concerning 30-min maximum values. We will generalize this result by showing that such a local measure is useful in quantifying GIC activity in a large surrounding power grid.

\section{Data and methods}

Because we consider the 30-min maximum of $|\mathrm{d} \mathbf{H} / \mathrm{d} t|$, we cannot directly determine the electric field from such a single value. However, we can use previously measured magnetic field time series from which we can derive an empirical relationship with the computed electric field at the given location.

We applied the EURISGIC ground conductivity models (Ádám et al. 2012; Viljanen et al. 2014) to calculate 1-min values of the electric fields in 1996-2008 at selected points in Europe using the method by Viljanen et al. (2012). The resulting time series were partitioned into 30 -min sequences (00:00-00:29 UT, 00:30-00:59, ...), and the maximum $|\mathrm{d} \mathbf{H} / \mathrm{d} t|$ and $|\mathbf{E}|$ for each of them were determined. We did not directly use the measured value of $|\mathrm{d} \mathbf{H} / \mathrm{d} t|$, but we always interpolated it from all available recordings using the method of spherical elementary current systems (SECS) by Amm \& Viljanen (1999). The SECS method uses as input observed variations of the ground magnetic field and provides as output an equivalent ionospheric current system that reproduces the observations. From the equivalent currents, we can calculate the ground field at any point. This ensures a uniform time series without gaps at all sites even if the measurements from a site were not available for all time steps. Although the magnetic field is then not precisely equal to the measured one, the interpolated value gives a reasonably accurate estimate (Pulkkinen et al. 2003; McLay \& Beggan 2010).

Calculated GIC values are based on the simplified power grid models introduced by Viljanen et al. (2012). We will consider the following cases: Nordic (Finland, Sweden, Norway), Baltic (Estonia, Latvia, Lithuania), British isles (UK, Ireland), Continent (continental Europe from Portugal in the west to Romania in the east; from Italy in the south to Denmark in the north). The measure used for GIC activity is the average current per node in the given grid model. So it represents a regional behaviour in contrast to the pointwise value of $|\mathrm{d} \mathbf{H} / \mathrm{d} t|$ or $|\mathbf{E}|$.

\section{Results}

\subsection{Relation between the electric field and time derivative of the magnetic field}

Figure 1 shows the sum of GIC in the Nordic high-voltage power grid, and the electric and magnetic fields at the Uppsala (UPS) geomagnetic observatory during the large magnetic storm on 30 October 2003. The 1-min time series demonstrates that high GIC levels are clearly related to $|\mathrm{d} \mathbf{H} / \mathrm{d} t|$ or to the modelled $|\mathbf{E}|$. Even a better correlation becomes evident when considering 30-min maximum values also plotted in the figure. We note that UPS is located at about $(60 \mathrm{~N}, 17 \mathrm{E})$, whereas the Nordic grid model covers the latitude range of about 55-70 N and longitude range of about 3-30 E. Consequently, a large part of the grid lies at several hundreds of kilometres away from UPS. Despite this, there is a pronounced relationship between the local quantities $|\mathrm{d} \mathbf{H} / \mathrm{d} t|$ and $|\mathbf{E}|$ to the regional sum of GIC. Later in this paper we will also consider the grid in the continental Europe, whose size is even much larger, and still find a similar relationship.

Figure 2 shows the relation between the 30-min maximum of $|\mathbf{E}|$ and $|\mathrm{d} \mathbf{H} / \mathrm{d} t|$ at four observatories in October 2003 (Wintoft et al. 2015). We note that the maximum $|\mathbf{E}|$ is not necessarily simultaneous with the maximum $|\mathrm{d} \mathbf{H} / \mathrm{d} t|$. However, there is a clear linear dependence at all sites with high 
A. Viljanen et al.: Regional estimation of geomagnetically induced currents
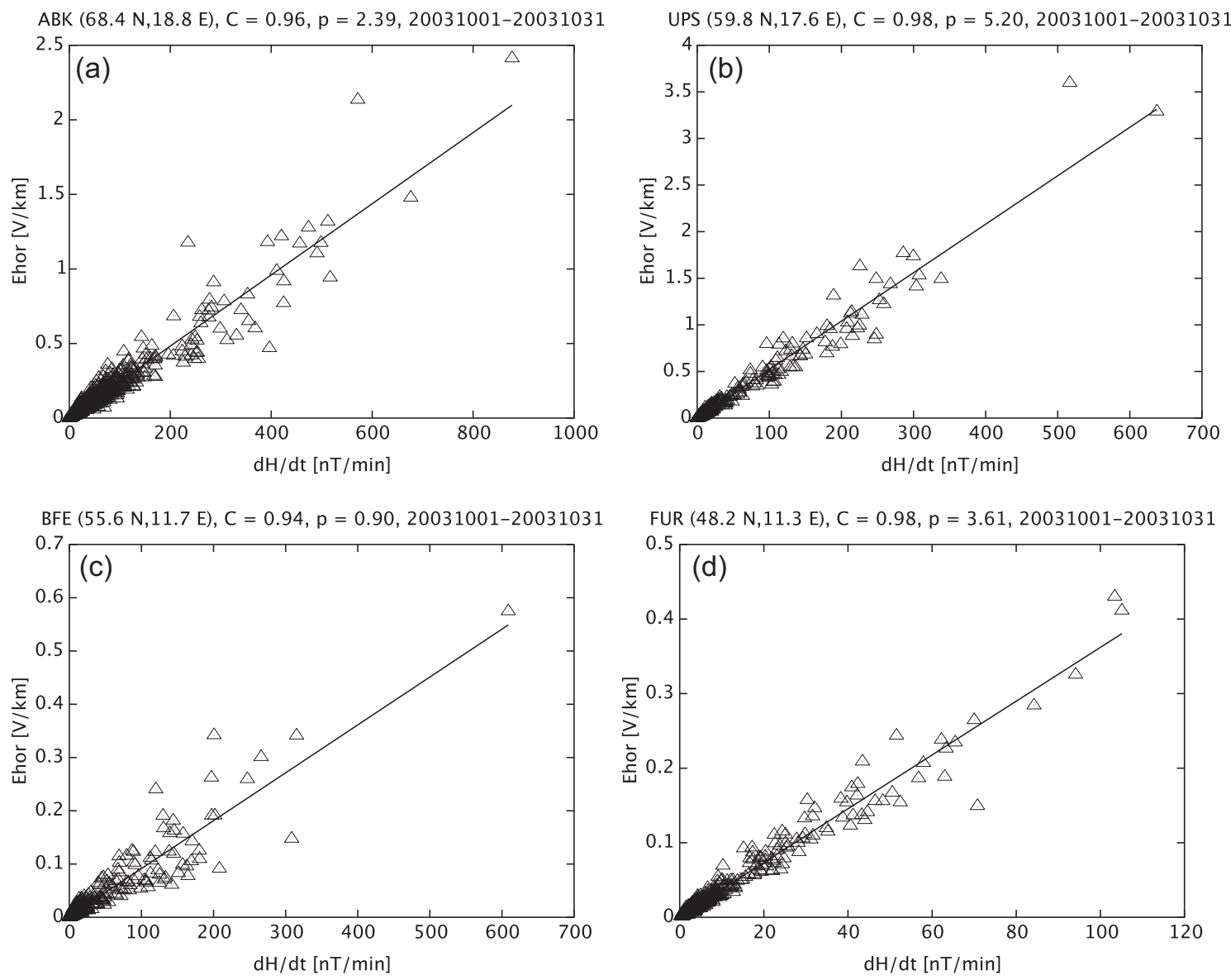

Fig. 2. Maximum of the modelled 1-min horizontal electric field versus the maximum of $|\mathrm{d} \mathbf{H} / \mathrm{d} t|$ for $30-$ min sequences 00:00-00:29, 00:30-00:59, .. UT in October 2003. (a) ABK, (b) UPS, (c) BFE, (d) FUR. $C$ is the linear correlation coefficient, $p$ is the slope of the fitted linear curve in $(\mathrm{mV} / \mathrm{km}) /(\mathrm{nT} / \mathrm{min})$. Figure adopted from Wintoft et al. (2015).

correlation coefficients. So we can simply express the maximum electric field as

$$
\max _{30}(|\mathbf{E}|)=p \times \max _{30}(|\mathrm{~d} \mathbf{H} / \mathrm{d} t|),
$$

where $p$ is an empirical coefficient specific for each site, and $\max _{30}$ refers to 30 -min sequences. The coefficient depends on the local (1-D) ground conductivity model. If we use a different model then we must recalculate $p$ too. In the following text, we will use the symbols $|\mathbf{E}|_{30}=\max _{30}(|\mathbf{E}|)$ and $|\mathrm{d} \mathbf{H} / \mathrm{d} t|_{30}=\max _{30}(|\mathrm{~d} \mathbf{H} / \mathrm{d} t|)$.

Figure 3 shows the monthly values of the coefficient $p$ of Eq. (1). Its variation from month to month in 1996-2008 is rather small, so it is reasonable to use a single value for each site, for which we select the average of the monthly values. Wintoft et al. (2015) provide the table of the coefficients at several European observatories, so we do not repeat them here.

\subsection{Regional GIC activity}

As shown above, $|\mathbf{E}|_{30}$ is highly correlated with $\mid \mathrm{d} \mathbf{H} / \mathrm{d} t t_{30}$, so the latter gives a good proxy for GIC too. The next step is to derive a quantitative dependence of GIC on the electric field in 30-min sequences. As the GIC measure, we use the sum of calculated currents through the neutral leads at substations similarly to Viljanen et al. (2012, 2014), and consider its 30-min maximum $\mathrm{GIC}_{30}=\max _{30}(\operatorname{sum}(\mathrm{GIC}) / N)$, where $N$ is the number of substations. It is then compared to the value of $|\mathrm{d} \mathbf{H} / \mathrm{d} t|_{30}$ or $|\mathbf{E}|_{30}$ at a single location.

An example of a monthly result is shown in Figure 4. There is a high linear correlation between $|\mathrm{d} \mathbf{H} / \mathrm{d} t|_{30}$ or $|\mathbf{E}|_{30}$ and $\mathrm{GIC}_{30}$. We have denoted the largest $1 \%$ of values separately in the figure by the red colour. In an ideal case, the set of the largest values of $\mid \mathrm{d} \mathbf{H} / \mathrm{d} t t_{30}$ or $|\mathbf{E}|_{30}$ would be equal to the corresponding set of $\mathrm{GIC}_{30}$. However, there is some scatter in the tail of the distribution: for a given large $|\mathrm{d} H / \mathrm{d} t|_{30}$ or $|\mathbf{E}|_{30}, \mathrm{GIC}_{30}$ can have a fairly large range. A similar feature is visible in $|\mathbf{E}|_{30}$ when plotted against $|\mathrm{d} \mathbf{H} / \mathrm{d} t|_{30}$ (Fig. 2).

Next, we repeated the calculations for the 13-year period of 1996-2008. Figure 5 shows histograms of $\mathrm{GIC}_{30}$ values that correspond to $|\mathrm{d} \mathbf{H} / \mathrm{d} t|_{30}$ at a given range. We note that even if $|\mathrm{d} \mathbf{H} / \mathrm{d} t|_{30}$ belongs to the largest percentile (top $1 \%$ of all values), $\mathrm{GIC}_{30}$ can still be at a relatively low level (down to about $2 \%$ of the maximum in 1996-2008). Only if $|\mathrm{d} \mathbf{H} / \mathrm{d} t|_{30}$ belongs to the largest permille (top $0.1 \%$ values), $\mathrm{GIC}_{30}$ nearly always reaches values equal to or larger than about $10 \%$ of the maximum in 1996-2008. We can also state that $|\mathrm{d} \mathbf{H} / \mathrm{d} t|_{30}$ must belong to the largest permille before the regional GIC is likely to reach values close to the maximum in 1996-2008.

An alternative way to present the results is shown in Figure 6. Instead of expressing the magnitude of GIC in amperes, we use percentile bins in the horizontal axis. An advantage is that this is not fixed to absolute values of 

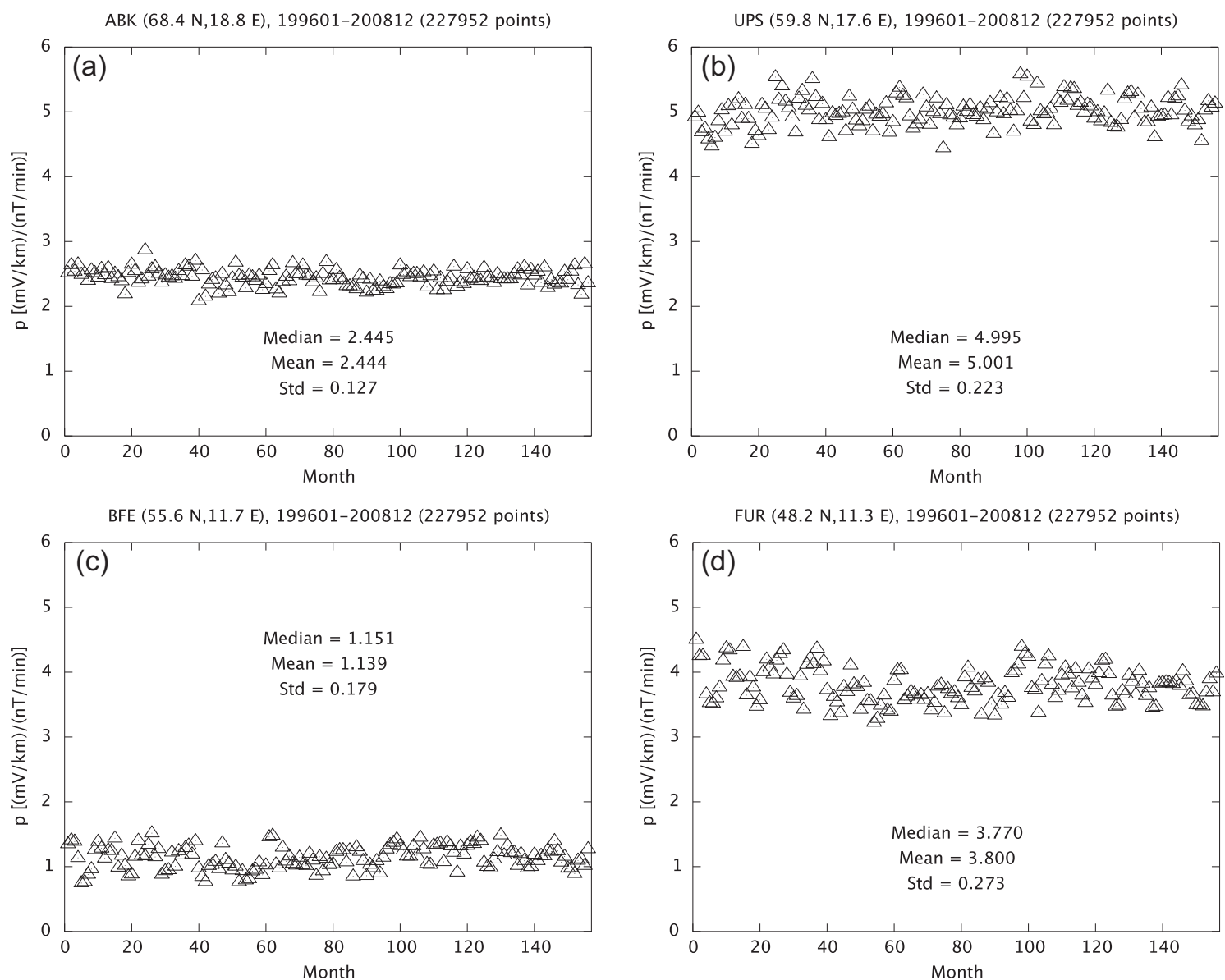

Fig. 3. Monthly mean values of the coefficient $p$ of Eq. (1) in 1996-2008. (a) ABK, (b) UPS, (c) BFE, (d) FUR. The number of points $(227,952)$ is the total number of 30 -min sequences in 1996-2008.
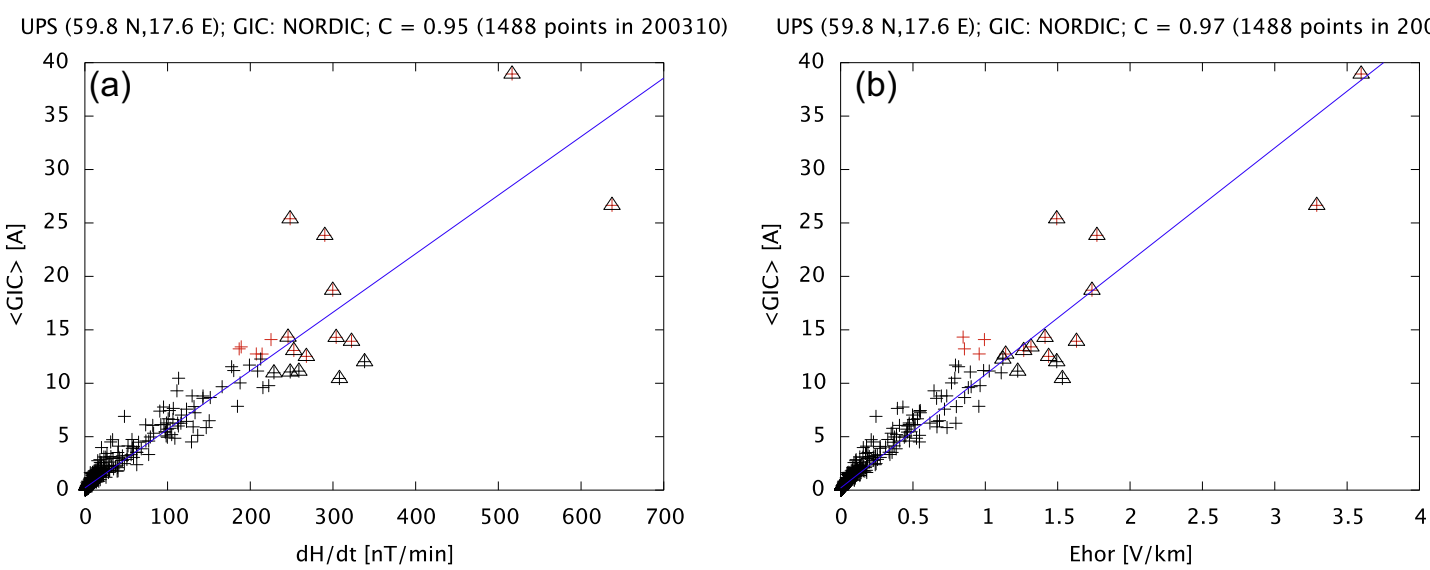

Fig. 4. 30-min maximum of the sum of GIC divided by the number of nodes in the Nordic high-voltage power grid in October 2003 as a function of $|\mathrm{d} \mathbf{H} / \mathrm{d} t|_{30}$ (a) and $|\mathbf{E}|_{30}$ (b) at UPS. Red crosses indicate the 15 largest values of $\mathrm{GIC}_{30}$. Triangles indicate the 15 largest values of $|\mathrm{d} \mathbf{H} / \mathrm{d} t|_{30}$ or $|\mathbf{E}|_{30}$. The blue curve is a fitted straight line.

GIC, but to a relative scale. In other words, given the percentile range of $|\mathrm{d} \mathbf{H} / \mathrm{d} t|_{30}$, we can assess the distribution of $\mathrm{GIC}_{30}$ with respect to the maximum within the period under study. In years 1996-2008, such reference events are 15 July 2000 and 29-30 October 2003 (Viljanen et al. 2014).

Table 1 collects results for a selected set of observatories corresponding to different parts of European high-voltage power grids. An expected result is that $\mathrm{GIC}_{30}$ is highest in
North Europe and decreases rapidly towards the south (Viljanen et al. 2014). The selection of an observatory to characterise GIC activity does not seem to be very sensitive. For example, both NUR (Nurmijärvi, Finland) and UPS (Uppsala, Sweden) yield nearly equal results for $\mathrm{GIC}_{30}$ in the Nordic grid. However, the observatory must not obviously be very far from the grid of interest. We tested this by using AQU (L'Aquila, Italy) to characterise $\mathrm{GIC}_{30}$ in the Nordic grid 
A. Viljanen et al.: Regional estimation of geomagnetically induced currents
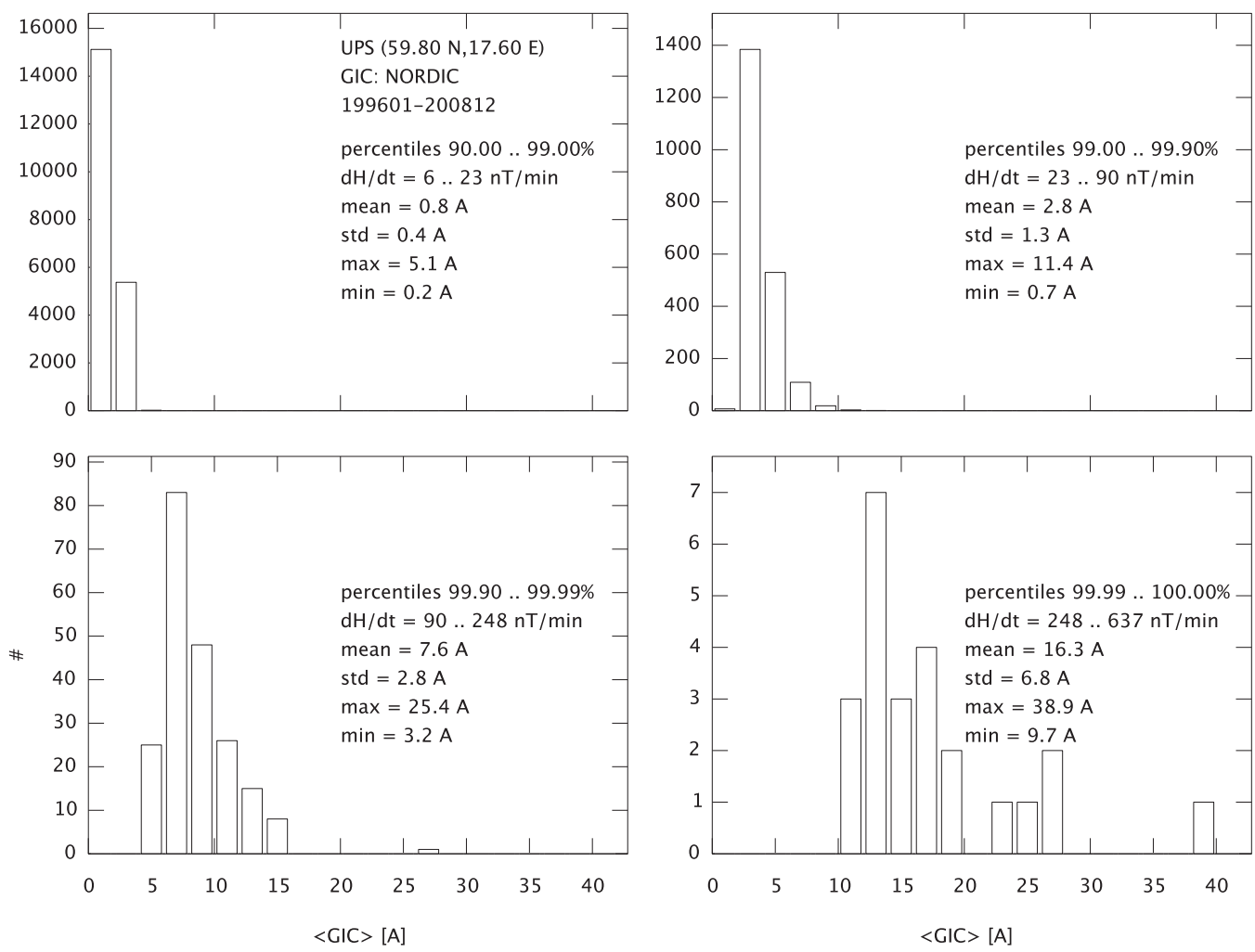

Fig. 5. Histograms of the 30-min maximum of the GIC sum divided by the number of nodes in the Nordic high-voltage power grid for different ranges of $|\mathrm{d} \mathbf{H} / \mathrm{d} t|_{30}$ at UPS. For example, the upper left plot shows the distribution when $|\mathrm{d} \mathbf{H} / \mathrm{d} t|_{30}$ varies between 6 and $23 \mathrm{nT} / \mathrm{min}$ which correspond to the percentile limits of $90 \%$ and $99 \%$, respectively. The total number of 30-min values in 1996-2008 is 227,952. The largest value of $\mathrm{GIC}_{30}$ is $38.9 \mathrm{~A}$.
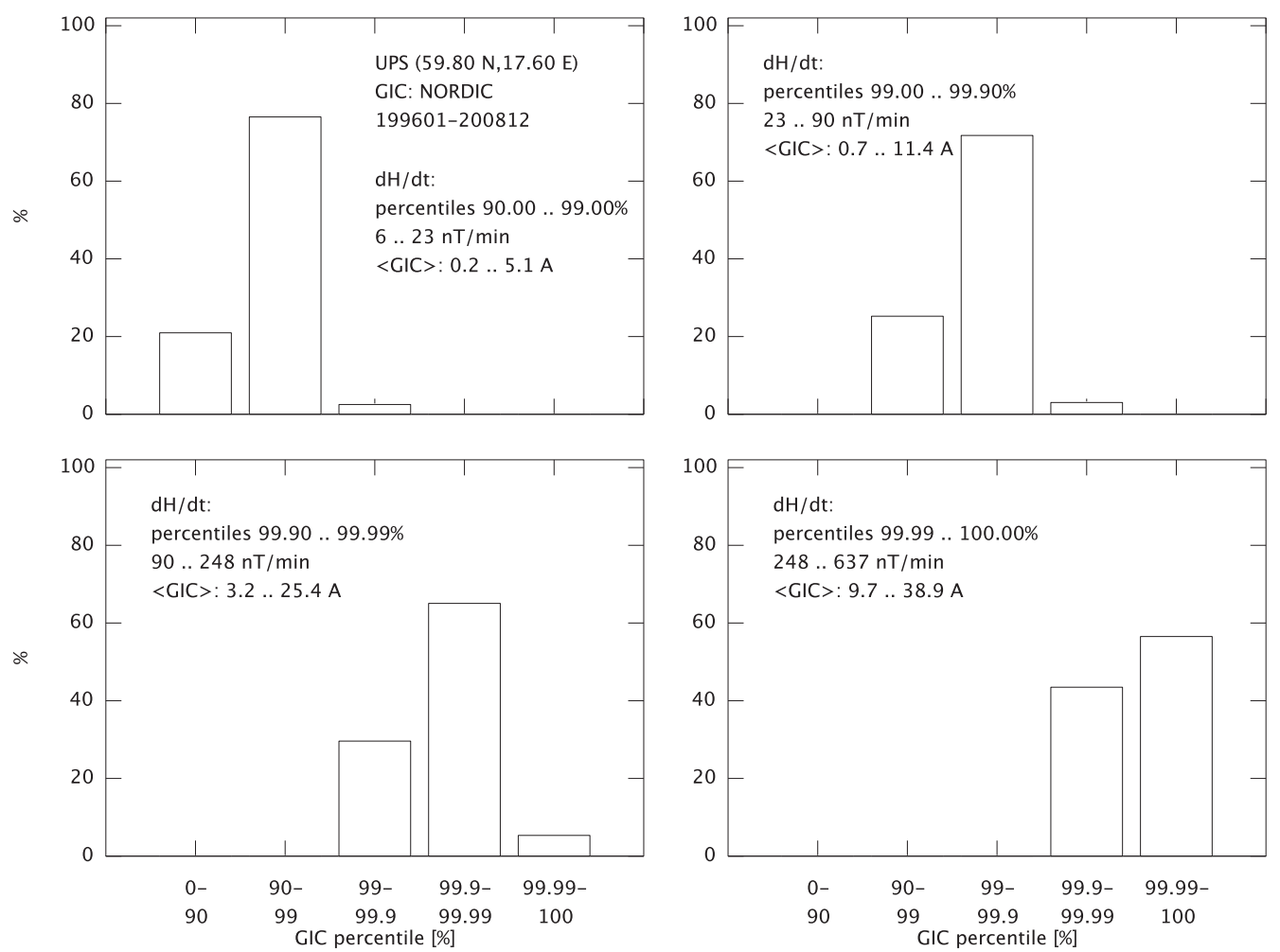

Fig. 6. Histograms of the 30-min maximum of the GIC sum divided by the number of nodes in the Nordic high-voltage power grid for different ranges of $|\mathrm{d} \mathbf{H} / \mathrm{d} t|_{30}$ at UPS. Percentile bins are used in the horizontal axis. The range of $\mathrm{GIC}_{30}$ in amperes is also given in each panel. For example, the upper left plot shows the distribution when $|\mathrm{d} \mathbf{H} / \mathrm{d} t|_{30}$ varies between 0.10 and $0.38 \mathrm{nT} / \mathrm{s}$ which correspond to the percentile limits of $90 \%$ and $99 \%$, respectively. Compare also to Figure 5. 
Table 1. Characteristics of $\mathrm{GIC}_{30}$ as a function of $|\mathrm{d} \mathbf{H} / \mathrm{d} t|_{30}$ at selected geomagnetic observatories. Columns (90-99\% etc.) refer to a set of sorted $|\mathrm{d} \mathbf{H} / \mathrm{d} t|_{30}$ values. For example, the first column is for $|\mathrm{d} \mathbf{H} / \mathrm{d} t|_{30}$ belonging to the largest $10 \%$ of all values excluding the top $1 \%$. For each observatory, we consider a specific grid model indicated below the observatory code. The three rows for each observatory contain the following information: range of $|\mathrm{d} \mathbf{H} / \mathrm{d} t|_{30}$, mean and standard deviation of $\mathrm{GIC}_{30}$, range of $\mathrm{GIC}_{30}$. The insert table gives corrected geomagnetic coordinates (CGM) calculated for the year 2002 (http://omniweb.gsfc.nasa.gov/vitmo/cgm_vitmo.html).

\begin{tabular}{|c|c|c|c|c|c|}
\hline Observatory grid & "90-99 & 99-99.9 & "99.9-99.99 & "99.99-100 & 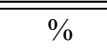 \\
\hline $\begin{array}{l}\text { UPS } \\
\text { Nordic }\end{array}$ & $\begin{array}{c}6-23 \\
0.8 \pm 0.4 \\
0.2-5.1\end{array}$ & $\begin{array}{c}23-90 \\
2.8 \pm 1.3 \\
0.7-11.4\end{array}$ & $\begin{array}{c}90-248 \\
7.6 \pm 2.8 \\
3.2-25.4\end{array}$ & $\begin{array}{r}248-637 \\
16.3 \pm 6.8 \\
9.7-38.9\end{array}$ & $\begin{array}{c}\mathrm{nT} / \mathrm{min} \\
\mathrm{A} \\
\mathrm{A}\end{array}$ \\
\hline $\begin{array}{l}\text { NUR } \\
\text { Nordic }\end{array}$ & $\begin{array}{c}7-27 \\
0.8 \pm 0.4 \\
0.1-4.8\end{array}$ & $\begin{array}{r}27-115 \\
2.8 \pm 1.3 \\
0.7-11.4\end{array}$ & $\begin{array}{c}115-300 \\
7.5 \pm 2.8 \\
2.9-25.4\end{array}$ & $\begin{array}{r}300-940 \\
15.5 \pm 6.8 \\
7.1-38.9\end{array}$ & $\begin{array}{c}\mathrm{nT} / \mathrm{min} \\
\mathrm{A} \\
\mathrm{A}\end{array}$ \\
\hline $\begin{array}{l}\text { NUR } \\
\text { Baltic }\end{array}$ & $\begin{array}{c}7-27 \\
0.5 \pm 0.2 \\
0.1-2.8\end{array}$ & $\begin{array}{c}27-115 \\
1.5 \pm 0.9 \\
0.3-7.1\end{array}$ & $\begin{array}{r}115-300 \\
4.4 \pm 2.2 \\
1.5-14.5\end{array}$ & $\begin{array}{r}300-940 \\
8.8 \pm 2.9 \\
3.1-13.7\end{array}$ & $\begin{array}{c}\mathrm{nT} / \mathrm{min} \\
\mathrm{A} \\
\mathrm{A}\end{array}$ \\
\hline $\begin{array}{l}\text { ESK } \\
\text { British }\end{array}$ & $\begin{array}{c}6-17 \\
0.4 \pm 0.1 \\
0.1-1.4\end{array}$ & $\begin{array}{c}17-64 \\
1.0 \pm 0.5 \\
0.3-4.7\end{array}$ & $\begin{array}{c}64-197 \\
3.2 \pm 1.2 \\
1.1-7.9\end{array}$ & $\begin{array}{r}197-573 \\
7.7 \pm 2.9 \\
3.4-13.5\end{array}$ & $\begin{array}{c}\mathrm{nT} / \mathrm{min} \\
\mathrm{A} \\
\mathrm{A}\end{array}$ \\
\hline $\begin{array}{l}\text { HAD } \\
\text { British }\end{array}$ & $\begin{array}{c}4-11 \\
0.4 \pm 0.1 \\
0.1-2.3\end{array}$ & $\begin{array}{c}11-35 \\
1.0 \pm 0.5 \\
0.2-5.1\end{array}$ & $\begin{array}{c}35-98 \\
3.1 \pm 1.5 \\
1.1-12.1\end{array}$ & $\begin{array}{r}98-302 \\
7.1 \pm 2.8 \\
3.3-13.5\end{array}$ & $\begin{array}{c}\mathrm{nT} / \mathrm{min} \\
\mathrm{A} \\
\mathrm{A}\end{array}$ \\
\hline $\begin{array}{l}\text { FUR } \\
\text { Continent }\end{array}$ & $\begin{array}{c}3-8 \\
0.2 \pm 0.1 \\
0.0-0.6\end{array}$ & $\begin{array}{c}8-25 \\
0.4 \pm 0.2 \\
0.2-1.5\end{array}$ & $\begin{array}{c}25-62 \\
1.1 \pm 0.4 \\
0.5-2.5\end{array}$ & $\begin{array}{c}62-184 \\
2.5 \pm 0.8 \\
1.4-4.3\end{array}$ & $\begin{array}{c}\mathrm{nT} / \mathrm{min} \\
\mathrm{A} \\
\mathrm{A}\end{array}$ \\
\hline $\begin{array}{l}\mathrm{AQU} \\
\text { Continent }\end{array}$ & $\begin{array}{c}3-8 \\
0.2 \pm 0.1 \\
0.0-0.6\end{array}$ & $\begin{array}{c}8-21 \\
0.4 \pm 0.2 \\
0.1-1.9\end{array}$ & $\begin{array}{c}21-48 \\
1.1 \pm 0.5 \\
0.2-2.7\end{array}$ & $\begin{array}{c}48-87 \\
2.4 \pm 0.9 \\
0.5-4.3\end{array}$ & $\begin{array}{c}\mathrm{nT} / \mathrm{min} \\
\mathrm{A} \\
\mathrm{A}\end{array}$ \\
\hline $\begin{array}{l}\text { AQU } \\
\text { Nordic }\end{array}$ & $\begin{array}{c}3-8 \\
0.8 \pm 0.6 \\
0.0-7.2\end{array}$ & $\begin{array}{c}8-21 \\
2.3-2.0 \\
0.1-16.0\end{array}$ & $\begin{array}{c}21-48 \\
6.1 \pm 4.0 \\
0.1-23.8\end{array}$ & $\begin{array}{r}48-87 \\
12.9 \pm 8.5 \\
1.3-38.9\end{array}$ & $\begin{array}{c}\mathrm{nT} / \mathrm{min} \\
\mathrm{A} \\
\mathrm{A}\end{array}$ \\
\hline Observatory & CGM lat & CGM lon & & & \\
\hline $\begin{array}{l}\text { NUR (Nurmijärvi, FI) } \\
\text { UPS (Uppsala, SE) } \\
\text { ESK (Eskdalemuir, UK) } \\
\text { HAD (Hartland, UK) } \\
\text { FUR (Fürstenfeldbruck, DE) } \\
\text { AQU (L'Aquila, IT) }\end{array}$ & $\begin{array}{l}56.9 \\
56.5 \\
52.6 \\
47.6 \\
43.4 \\
36.2\end{array}$ & $\begin{array}{r}102.1 \\
95.8 \\
77.2 \\
74.7 \\
86.8 \\
87.3\end{array}$ & & & \\
\hline
\end{tabular}

more than $1000 \mathrm{~km}$ north of AQU. As the last rows in Table 1 show, estimates for GIC levels are then more scattered, although the difference from the result by NUR or UPS is not as large as could have been intuitively expected. This observation may give rise to further analysis of scale lengths of geomagnetic variations.

\section{Conclusions}

Previous studies have indicated a high correlation between $|\mathrm{d} \mathbf{H} / \mathrm{d} t|$ and GIC at single substations of power grids. Our results show that the 30 -min maximum of the time derivative of the horizontal magnetic field $\left(|\mathrm{d} \mathbf{H} / \mathrm{d} t|_{30}\right)$ at a single point yields a proxy for GIC activity in a larger region as measured by the average current per node in given grid. A practical consequence is that if $|\mathrm{d} \mathbf{H} / \mathrm{d} t|_{30}$ can be predicted at some point then it is also possible to assess the expected GIC level in a surrounding area. Long-term statistics of $|\mathrm{d} \mathbf{H} / \mathrm{d} t|_{30}$ is often available, so it is possible to quantify how rare GIC events can be expected given a forecasted $|\mathrm{d} \mathbf{H} / \mathrm{d} t|_{30}$.
The use of geomagnetic activity indices such as $K, A_{k}, A_{p}$ in the past to estimate GIC activity (e.g. Campbell 1978; Boteler et al. 1982; Lundby et al. 1985) has restrictions due to the fixed range of index values (Kappenman 2005). This is problematic concerning the largest geomagnetic events that are also the most probable ones to cause immediate major effects on power grids. As shown in this paper, the electric field $\left(|\mathbf{E}|_{30}\right)$ and $\mathrm{GIC}_{30}$ are nearly linearly related to $|\mathrm{d} \mathbf{H} / \mathrm{d} t|_{30}$, so there is no saturation with increasing geomagnetic activity.

We should note the scatter related to rare large events. A corresponding feature was noted, for example, by Pulkkinen et al. (2012) who studied 100-year scenarios of GIC, and considered the distribution of the modelled electric field and its extrapolation to 1 -in-100 year value in their Figure 1. There is a notable uncertainty range in the estimated extreme value. Thomson et al. (2011) faced the same feature when deriving 100 - and 200-year extrapolations to the magnetic variation field and its time derivative. However, our Table 1 gives a guideline with error limits for estimating expected GIC magnitudes at a given level of geomagnetic activity as defined by $|\mathrm{d} \mathbf{H} / \mathrm{d} t|_{30}$. 
A. Viljanen et al.: Regional estimation of geomagnetically induced currents

We have also demonstrated that a local geomagnetic recording can be used to estimate GIC levels in a wider region than just close to an observatory. This is a useful result especially if there are only few magnetometer stations in the area of a power grid, which restricts the full accurate modelling of GIC.

Acknowledgements. The research leading to these results received funding from the European Community's Seventh Framework Programme (FP7/2007-2013) under Grant Agreement No. 260330 (EURISGIC). We thank the institutes maintaining geomagnetic observatories in Europe. The editor thanks Cleiton da Silva Barbosa and an anonymous referee for their assistance in evaluating this paper.

\section{References}

Ádám, A., E. Prácser, and V. Wesztergom. Estimation of the electric resistivity distribution (EURHOM) in the European lithosphere in the frame of the EURISGIC WP2 project. Acta Geod. Geoph. Hung., 47, 377-387, 2012, DOI: 10.1556/AGeod.47.2012.4.1.

Amm, O., and A. Viljanen. Ionospheric disturbance magnetic field continuation from the ground to the ionosphere using spherical elementary current systems. Earth Planets Space, 51, 431-440, 1999, DOI: 10.1186/BF03352247.

Boteler, D. Methodology for simulation of geomagnetically induced currents in power systems. J. Space Weather Space Clim., 4, A21, 2014, DOI: $10.1051 / \mathrm{swsc} / 2014018$.

Boteler, D.H., and R.J. Pirjola. Comparison of methods for modelling geomagnetically induced currents. Ann. Geophys., 32, 1177-1187, 2014, DOI: 10.5194/angeo-32-1177-2014.

Boteler, D.H., T. Watanabe, R.M. Shier, and R.E. Horita. Characteristics of geomagnetically induced currents in the B.C. Hydro $500 \mathrm{kV}$ system. IEEE T. Power Appar. Syst., PAS-101, 1447-1456, 1982, DOI: 10.1109/TPAS.1982.317192.

Campbell, W.H. Induction of auroral zone electric currents within the alaska pipeline. Pure Appl. Geophys., 116, 1143-1172, 1978, DOI: $10.1007 /$ BF00874677.

Gleisner, H., and H. Lundstedt. A neural network-based local model for prediction of geomagnetic disturbances. J. Geophys. Res., 106 (A5), 8425-8433, 2001, DOI: 10.1029/2000JA900142.

Hejda, P., and J. Bochnicek. Geomagnetically induced pipe-to-soil voltages in the Czech oil pipelines during October-November 2003. Ann. Geophys., 23, 3089-3093, 2005, DOI: 10.5194/angeo-23-3089-2005.

Kappenman, J.G. An overview of the impulsive geomagnetic field disturbances and power grid impacts associated with the violent Sun-Earth connection events of 29-31 October 2003 and a comparative evaluation with other contemporary storms. Space Weather, 3, S08C01, 2005, DOI: 10.1029/2004SW000128.

Lehtinen, M., and R. Pirjola. Currents produced in earthed conductor networks by geomagnetically-induced electric fields. Ann. Geophys., 3, 479-484, 1985.

Lundby, S., B.E. Chapel, D.H. Boteler, T. Watanabe, and R.E. Horita. Occurrence frequency of geomagnetically induced currents: a case study on a B.C. Hydro $500 \mathrm{kV}$ power line. J. Geomag. Geoelectr., 37, 1097-1114, 1985, DOI: $10.5636 /$ jgg.37.1097.

McLay, S.A., and C.D. Beggan. Ann. Geophys. 28, 1795-1805, 2010, DOI: 10.5194/angeo-28-1795-2010.

Ngwira, C.M., A. Pulkkinen, L.-A. McKinnell, and P.J. Cilliers. Improved modeling of geomagnetically induced currents in the South African power network. Space Weather, 6, S11004, 2008, DOI: $10.1029 / 2008$ SW000408.

Pulkkinen, A., O. Amm, A. Viljanen, and BEAR Working Group. Ionospheric equivalent current distributions determined with the method of spherical elementary current systems. J. Geophys. Res., 108 (A2), 1053, 2003, DOI: 10.1029/2001JA005085.
Pulkkinen, A., M. Hesse, S. Habib, L. Van der Zel, B. Damsky, F. Policelli, D. Fugate, W. Jacobs, and E. Creamer. Solar shield: forecasting and mitigating space weather effects on high-voltage power transmission systems. Nat. Hazards, 53, 333-345, 2010a, DOI: $10.1007 / \mathrm{s} 11069-009-9432-x$.

Pulkkinen, A., R. Kataoka, S. Watari, and M. Ichiki. Modeling geomagnetically induced currents in Hokkaido, Japan. $A d v$. Space Res., 46, 1087-1093, 2010b, DOI: $10.1016 /$ j.asr.2010.05.024.

Pulkkinen, A., E. Bernabeu, J. Eichner, C. Beggan, and A.W.P. Thomson. Generation of 100-year geomagnetically induced current scenarios. Space Weather, 10, S04003, 2012, DOI: 10.1029/2011SW000750.

Pulkkinen, A., L. Rastätter, M. Kuznetsova, H. Singer, C. Balch, et al. Community-wide validation of geospace model ground magnetic field perturbation predictions to support model transition to operations. Space Weather, 11, 369-385, 2013, DOI: $10.1002 /$ swe.20056.

Thomson, A.W.P., A.J. McKay, E. Clarke, and S.J. Reay. Surface electric fields and geomagnetically induced currents in the Scottish Power grid during the 30 October 2003 geomagnetic storm. Space Weather, 3, S11002, 2005, DOI: $10.1029 / 2005$ SW000156.

Thomson, A., E. Dawson, and S. Reay. Quantifying Extreme Behaviour in Geomagnetic Activity. Space Weather, 9, S10001, 2011, DOI: 10.1029/2011SW000696.

Tóth, G., X. Meng, T.I. Gombosi, and L. Rastätter. Predicting the time derivative of local magnetic perturbations. J. Geophys. Res. [Space Phys.], 119, 310-321, 2014,

DOI: 10.1002/2013JA019456.

Trichtchenko, L., and D.H. Boteler. Modeling geomagnetically induced currents using geomagnetic indices and data. IEEE T. Plasma Sci., 32, 1459-1467, 2004,

DOI: $10.1109 /$ TPS.2004.830993.

Trichtchenko, L., A. Zhukov, R. van der Linden, S.M. Stankov, N. Jakowski, et al. November 2004 space weather events: Real-time observations and forecasts. Space Weather, 5, S06001, 2007, DOI: $10.1029 / 2006$ SW000281.

Viljanen, A. The relation between geomagnetic variations and their time derivatives and implications for estimation of induction risks. Geophys. Res. Lett., 24, 631-634, 1997,

DOI: 10.1029/97GL00538.

Viljanen, A. Relation of geomagnetically induced currents and local geomagnetic variations. IEEE Trans. Power Delivery, 13, 1285-1290, 1998, DOI: 10.1109/61.714497.

Viljanen, A., H. Nevanlinna, K. Pajunpää, and A. Pulkkinen. Time derivative of the horizontal geomagnetic field as an activity indicator. Ann. Geophys., 19, 1107-1118, 2001, DOI: 10.5194/angeo-19-1107-2001.

Viljanen, A., R. Pirjola, M. Wik, A. Adam, E. Pracser, Ya. Sakharov, and Yu. Katkalov. Continental scale modelling of geomagnetically induced currents. J. Space Weather Space Clim., 2, A17, 2012, DOI: $10.1051 / \mathrm{swsc} / 2012017$.

Viljanen, A., R. Pirjola, E. Pracser, J. Katkalov, and M. Wik. Geomagnetically induced currents in Europe. Modelled occurrence in a continent-wide power grid. J. Space Weather Space Clim., 4, A09, 2014, DOI: 10.1051/swsc/2014006.

Watari, S., M. Kunitake, K. Kitamura, T. Hori, T. Kikuchi, et al. Measurements of geomagnetically induced current in a power grid in Hokkaido, Japan. Space Weather, 7, S03002, 2009, DOI: $10.1029 / 2008$ SW000417.

Weigel, R.S., A.J. Klimas, and D. Vassiliadis. Solar wind coupling to and predictability of ground magnetic fields and their time derivatives. J. Geophys. Res., 108 (A7), 1298, 2003, DOI: 10.1029/2002JA009627.

Wintoft, P. Study of the solar wind coupling to the time difference horizontal geomagnetic field. Ann. Geophys., 23, 1949-1957, 2005, DOI: 10.5194/angeo-23-1949-2005. 
J. Space Weather Space Clim., 5, A24 (2015)

Wintoft, P., M. Wik, H. Lundstedt, and L. Eliasson. Predictions of local ground geomagnetic field fluctuations during the 7-10 November 2004 events studied with solar wind driven models. Ann. Geophys., 23, 3095-3101, 2005,

DOI: 10.5194/angeo-23-3095-2005.
Wintoft, P., M. Wik, and A. Viljanen. Solar wind driven empirical forecast models of the time derivative of the ground magnetic field. J. Space Weather Space Clim., 5, A7, 2015, DOI: $10.1051 / \mathrm{swsc} / 2015008$.

Cite this article as: Viljanen A, Wintoft P \& Wik M. Regional estimation of geomagnetically induced currents based on the local magnetic or electric field. J. Space Weather Space Clim., 5, A24, 2015, DOI: 10.1051/swsc/2015022. 